REVISTA DE DERECHO UNED, NÚM. 27, 2021

\title{
LOS DERECHOS DE PARTICIPACIÓN POLÍTICA EN LOS ORÍGENES DEL CONSTITUCIONALISMO VENEZOLANO $^{1}$
}

\section{THE RIGHTS OF POLITICAL PARTICIPATION IN THE ORIGINS OF VENEZUELAN CONSTITUTIONALISM}

\author{
CAYETANo NúÑEZ RIVERo (UNED) JOSE.NUNEZ@DER.UNED.ES
}

Ani Urse (ULAC)

Sumario: 1. Introducción. 2. La Junta Suprema de España. 3. La Junta de Caracas. 4. El Reglamento de 1810. 5. La Constitución de 1811. 6. La Constitución de 1819.

Resumen: La primera vez que se hace mención a la representación del pueblo se produce como consecuencia de la formación de la Junta de Caracas en la que se indicaba que dicho organismo debería contar con una representación del "pueblo". Constituida la Junta, ésta convocó elecciones para configurar un proceso constituyente, mediante un Reglamento de elecciones. El documento citado parte de una defensa de los principios de participación política y de democracia representativa, por sistema mayoritario a pluralidad de votos. El sufragio es de carácter censitario y capacitario, con grandes restricciones de carácter económico. La Democracia representativa se proclama en el texto de 1811, que emplea el término Pueblo y no Nación, estableciendo el voto indirecto y el sufragio censitario, por motivos económicos, tanto de carácter activo como pasivo. En la convocatoria al proceso constituyente de 1812, así como en el texto

${ }^{1}$ Este trabajo se lleva a cabo dentro de las líneas de Investigación correspondientes al Doctorado en Derecho y Ciencias Sociales de la Facultad de Derecho de la Universidad Nacional de Educación a Distancia de España (UNED). 
constitucional de 1819, se introduce el concepto de que los diputados electos al Congreso no sólo serán representantes de su provincia, sino de toda la Nación, manteniendo los mismos criterios sobre el sufragio que el texto anterior.

Palabras claves: Venezuela, Nación, Constitución, Soberanía, Democracia representativa, sufragio.

Abstract: The first time that the representation of the people is mentioned, it occurs as a consequence of the formation of the Junta de Caracas in which it was indicated that said body should have a representation of the "people". Once the Board was constituted, it called elections to configure a constituent process, through an Election Regulation. The aforementioned document starts from a defense of the principles of political participation and representative democracy, by majority system to plurality of votes. Suffrage is census and capacity, with great economic restrictions. Representative Democracy is proclaimed in the text of 1811, which uses the term People and not Nation, establishing indirect voting and census suffrage, for economic reasons, both active and passive. In the call to the constitutional process of 1812 , as well as in the constitutional text of 1819, the concept is introduced that the deputies elected to Congress will not only be representatives of their province, but of the entire Nation, maintaining the same criteria on suffrage than the previous text.

Key Words: Venezuela, Nation, Constitution, Sovereignty, representative democracy, suffrage.

Recepción original: 2-7-2020

Aceptación original: 10-10-2020

\section{INTRODUCCIÓN.}

En primer lugar tenemos que situarnos en el momento histórico en el que se producen o se anuncian los primeros procesos electorales correspondientes a la conformación del primer Estado de Derecho en el ámbito cultural, social y económico hispanoamericano.

Hasta ese momento la experiencia en procesos electorales era mínima, circunscribiéndose a los casos norteamericano y francés, y en cierta medida al peculiar caso inglés, únicos estados en los que el Antiguo Régimen había sido desplazado por la emergencia del Primer Estado Liberal. Sin embargo, el punto de partida en el aspecto 
social y cultural entre estos Estados y el que se produce tanto en la España metropolitana como en América son muy diferentes.

Así, mientras la caída del Antiguo Régimen en los primeros países citados es consecuencia de la ruptura de la sociedad estamental imperante, en virtud del desarrollo de la emergencia de clases sociales, especialmente la burguesía, valga recordar el desarrollo de las sociedades financieras y navieras en Holanda, la actividad de las bolsas de Marsella o París, el proceso de aburguesamiento de la nobleza británica o del ennoblecimiento de la burguesía inglesa, todo ello, en virtud de un desarrollo económico al que el poder político impedía consolidarse. Por tanto, lo que se produce en lo que al tema electoral se refiere en los países citados, es un intento de aniquilar el sistema existente- Antiguo Régimen-, mediante la representación de la nueva clase social ascendente: la burguesía, que será la única que obtendrá representación y derecho al voto, así la nobleza, no tendrá representación, salvo en la medida que se convierta en clase burguesa y represente a la misma, sea en el sector agrario, fiduciario o industrial; evidentemente la clase trabajadora no formaba parte de este diseño feliz. Por tanto los cambios filosóficos, ideológicos, políticos y al final jurídicos acaecidos son consecuencia del desarrollo económico y no al revés.

Por el contrario, si nos centramos en el mundo hispanoamericano, el panorama que se nos presenta es muy diferente, no podemos hablar de la existencia de una burguesía propiamente dicha, salvo pequeños núcleos de acumulación precapitalista en contados puntos de la península: Madrid (Reales Fábricas, creadas por la Corona) Barcelona (talleres textiles),Bilbao (exportación e importación) y el eje Sevilla-Cádiz (ligado al comercio de Indias y controlado igualmente por el monopolio estatal), y en el continente americano la realidad no se nos presenta mejor, se trata de una sociedad fundamentalmente agraria de carácter terrateniente en manos de un reducido estamento aristócrata o de la Jerarquía Católica y dentro del concepto estamental en la organización social. Sólo un reducido grupo de hacendados exportadores opuestos al férreo control de la Corona al respecto, podían representar intereses cercanos al concepto de burguesía imperante en los Estados Unidos o en el continente europeo.

De esta forma, no podemos hablar de la existencia de una clase social burguesa, diferenciada de la organización estamental ni en España ni en el continente americano. No obstante, ello no quiere decir que las ideas ilustradas y "revolucionarias" no hubieran penetrado en el mundo hispánico, sí lo hicieron, pero no como con- 
secuencia de una necesidad de desarrollo económico, sino simplemente de importación de ideas por un sector minoritario de la nobleza media, tal es el caso de la formación de las denominadas "Sociedades de Amigos del País", "Sociedades económicas " etc. donde las ideas ilustradas tenían cabida y de alguna forma intentaban la modernización del país en algunos aspectos como la cultura, la agricultura, la economía en general etc, aunque sin que ello significara cuestionamiento alguno del orden político existente, como consecuencia de la difusión de las ideas ilustradas.

No obstante ha de indicarse que la difusión de las ideas revolucionarias e incluso de la ilustración estuvieron sujetas a un férreo control por parte de la Corona y sobre todo por parte de la Inquisición, de tal forma que era muy difícil acceder a los libros originales y sólo podía hacerse mediante mediocres traducciones o discutibles interpretaciones, valga recordar al respecto que en el continente americano el mayor difusor de las ideas ilustradas fue la Compañía de Jesús, lo que significa claramente que la Ilustración que se va a conocer no es consecuencia de la herencia de la cultura cartesiana y de la razón, sino que tiene en su base las raíces religiosas y sus limitaciones dogmáticas. Con ello no se quiere dejar de reconocer la importante tarea renovadora que trascendió desde los centros de formación de la Compañía de Jesús y donde se educaba la casi totalidad de la aristocracia criolla, así como de centros como la Universidad de Santo Tomás de Aquino, Real Colegio de San Carlos, Universidad del Rosario, San Marcos, etc, y todo ello sujeto a un férreo control inquisitorial, que como dijo el Ministro ilustrado Jovellanos en un memorandum dirigido al Rey Carlos IV, " "son gentes que ignoran lenguas extrañas, que solo saben un poco de teología escolástica $y$ de moral eclesiástica". ${ }^{2}$

En todo caso debe reconocerse a los centros educativos de la Compañía de Jesús en las Indias la idea de que sobre el poder de la nobleza de sangre debía imponerse la del mérito y la educación.

En suma, debemos coincidir con Juan Lynch, cuando indica que las ideas ilustradas entran tardíamente en América despojadas de su ideología y reducidas a un programa de modernización dentro del orden establecido. ${ }^{3}$

Ello no quiere decir que a principios del siglo XIX no circularan por todo el continente obras de Rousseau, el Contrato Social funda-

2 Informe de Jovellanos al Rey Carlos IV.

3 Lynch,Juan; (2005)"La revolución hispanoamericana 1808-1826". Ed. Ariel. Barcelona . 
mentalmente, así como de Voltaire, y otros enciclopedistas, y por supuesto se tenía conocimiento de los sucesos de la Francia revolucionaria y de los cambios acaecidos en la América del Norte.

Sentado pues el principio del bajo nivel social y cultural previo a la conformación del Estado de Derecho en el ámbito de la Corona española, pasaremos ahora a las características de nuestros primeros procesos de participación política y la regulación jurídica de los mismos.

Lo primero que debemos tener en cuenta es que los cambios políticos son consecuencia de un hecho fortuito: la invasión napoleónica de la península ibérica y no de un proceso continuado y progresivo anterior.

\section{LA JUNTA SUPREMA DE ESPAÑA}

La primera convocatoria electoral es la que lleva a cabo por la Junta Suprema de España, el 22 de febrero de 1809 que dicta un decreto por el que declara que los vastos territorios de indias no son colonias sino, sino parte esencial e integrante de la Monarquía Española, por lo que manda que los reinos y provincias americanas envíen diputados que los representen en dicha Junta.

Los representantes americanos fueron elegidos según decreto de 14 de febrero de 1810. En este caso eran los ayuntamientos los que elegían a los diputados. Por primera vez estos territorios dejan de tratarse como colonias para pasar a tener la consideración de provincias.

Sobre esta convocatoria debemos destacar que el único derecho electoral perceptible es el de la convocatoria y su forma de elección, pero debe destacarse que los representantes lo fueron por el Cabildo municipal de la capital del Virreinato o Gobernación, lo que implicaba un cambio fundamental en la organización del poder, pues hasta ese momento la representación la detentaba exclusivamente el Virrey y los otros cargos designados por los diferentes órganos de la Corona, a través de los cuales se expresaba el poder de la Corona.

Sobre el funcionamiento de las entidades municipales debe indicarse, que aunque contaban con diversos componentes funcionarios de designación directa por las autoridades establecidas, desde la reforma de 1766 del Rey Carlos III, se crearon oficios electos por los vecinos que elegían a sus síndicos, personeros del común y alcaldes de barrio sin distinción ni estamento. 
Sobre este proceso electoral valga destacar en este momento que uno de los argumentos esgrimidos para la configuración de las Juntas Americanas fue que la Junta establecida en España representaba a las diversas Juntas provinciales de España, pero de América sólo a la de la ciudad que había designado al representante, por lo que procedieron a conformar nuevas Juntas cuya representación correspondiera a la totalidad de su territorio, en igualdad de condiciones con la Junta metropolitana española, lo que indudablemente contribuyó de forma decisiva a la conformación del concepto Nación y por ende a la proclamación de la soberanía nacional.

\section{LA JUNTA DE CARACAS.}

La primera vez que se hace mención a la representación del pueblo se produce como consecuencia de la formación de la Junta de Caracas, en virtud de los graves acontecimientos acaecidos en España con motivo de la entronización de la Casa de Bonaparte, que sustituirá a la de Borbón, dando lugar a la denominada "Guerra de la Independencia"4 y a la formación en el territorio peninsular de Juntas locales y provinciales que coordinaban la lucha española contra las tropas napoleónicas, y que culminaría el 27 de mayo en la conformación de la Junta de Sevilla, como Junta Central, que se acabaría denominando como Junta Suprema de España y de Indias y que aglutinaría los poderes ejecutivos y legislativos de la España insurgente. A este respecto, el Capitán General Don Juan de Casas, remitió un escrito al Ayuntamiento caraqueño, en el que le manifestaba su deseo de que se constituyera una Junta semejante a las organizadas en la Península Ibérica, que fue aprobada por el Ayuntamiento, siendo presidida por el Capitán General, que contaría como integrantes del mismo a los miembros del Ayuntamiento, así como al Arzobispo, el Regente y el Fiscal de la Audiencia, el Intendente del ejército, así como otras autoridades reales, proponiendo igualmente una representación del Cabildo eclesiástico y otros representantes del clero regular y secular, a los que se sumarían personas designadas por el grupo de comerciantes y propiedades agrícolas y del Colegio de Abogados, indicando igualmente, que dicho organismo debería contar con una representación del "pueblo".

4 Se conoce como Guerra de la Independencia española, el periodo de 1808 a 1814, que enfrentó al pueblo español contra las tropas napoleónicas; durante este periodo se celebraron las Cortes de Cádiz, que promulgó la Constitución de 1812. 
La inclusión de este concepto de representación fue utilizado por el denominado grupo "Mantuano", que eran una parte importante de la nobleza criolla, y que ya en este momento sostenía posturas claramente independentistas, aunque defendieran la legitimidad de Fernando VII en contra de la del Rey José I; de esta forma el citado grupo, asumiendo una representación del "pueblo", que difícilmente podían sustentar en principios democráticos, siendo más bien propia de una sociedad estamental, sujeta a principios marcadamente censitarios y de un sistema de cooptación, designaron a varias personas $^{5}$; no obstante dicho nombramiento no fue aceptado por el Capitán General.

Destituido el General Emparán y otras altas autoridades españolas, el 19 de abril de 1810 se constituyó la Junta Suprema de Caracas, compuesta por veintitrés miembros, denominada "Conservadora de los derechos de Fernando VII", ${ }^{6}$ mediante la transformación del Cabildo de Caracas en la misma, a la que por primera vez en la historia se incluiría el denominado "Cabildo de los pardos"

\section{EL REGLAMENTO DE 1810.}

El diez de junio de 1810, la Junta convoca elecciones, publicando un Reglamento de elecciones al respecto, con el fin de configurar un Congreso Constituyente, "Reglamento para la elección y reunión de diputados que han de componer el Cuerpo Conservador de los Derechos del Sr. D. Fernando VII en las Provincias de Venezuela".

La convocatoria tiene un ámbito coincidente con el del nuevo Estado que se quiere crear, y desea dotar del principio de participación a la ciudadanía:

"Habitantes de Venezuela:"

La Junta Suprema de estas provincias, al revestirse del alto carácter que una parte considerable de vosotros le ha conferido, no pudo disimular que la naturaleza y términos de su constitución le imponían imperiosamente la necesidad de convocaros para consultar vuestros votos y para que escogieseis inmediatamente las personas que por su probidad, luces y patriotismo os parecieran dignas de vuestra confianza. Veía la Junta que antes de la reunión de los diputados provinciales sólo incluía la representación del pueblo de la capital, y que aún después de admitidos en su seno los de Cumaná, Barcelona y Margarita quedaban sin voz alguna representativa las ciudades y pueblos de lo interior,

7 En todos los documentos mencionados en el presente trabajo se conserva la redacción ortográfica original.

(C) UNED. Revista de Derecho UNED, núm. 27, 2021 
tanto de ésta como de las otras provincias; veía que la proporción en que se hallaba el número de los delegados de Caracas con los del resto de la Capitanía General no se arreglaba, como lo exige la naturaleza de tales delegaciones, al número de los comitentes: veía por último que si la estrechez de las circunstancias era una apología suficiente para estos defectos, dejaría de serlo si descuidaba remediarlos inmediatamente que pareciese llegada la época de verificarlo sin inconvenientes, sin desorden y de una manera que calificase la vigilante solicitud de la Junta por la tranquilidad pública; al mismo tiempo que hiciese presente la moderación y equidad de sus principios (...)"

En la convocatoria, la Junta proclama la necesidad de contar con un Gobierno independiente de las autoridades españolas, aunque sigue reconociendo la figura de Fernando VII como Rey.

"Conoce la Junta Suprema la necesidad de un poder Central bien constituido, y cree es llegado el momento de organizarlo. ¿Cómo se podrían de otro modo trazar los límites de la autoridad de las Juntas provinciales, corregir los vicios de que también adolece la constitución de éstas, dar a las provincias gubernativas aquella unidad sin la cual no puede haber ni orden, ni energía; consolidar un plan defensivo que nos ponga a cubierto de toda clase de enemigos; formar, en fin, una confederación sólida, respetable, ordenada, que restablezca de todo punto la tranquilidad y confianza, que mejore nuestras instituciones y a cuya sombra podamos aguardar la disipación de las borrascas políticas que están sacudiendo al universo, conservar integros los derechos de nuestro desgraciado monarca y las leyes fundamentales de su Corona?(...)"9

Aunque niega la autoridad del Consejo de Regencia instaurado en España sobre el territorio venezolano, ${ }^{10}$

"Es demasiado evidente que la Junta Central de España no representaba otra parte de la nación que el vecindario de las capitales en que se formaban las Juntas provinciales, que enviaron sus diputados a componerla; de que resulta que este cuerpo no pudo ser soberano sino durante el influjo de la necesidad, es decir, durante el tiempo que tardase en constituirse una verdadera representación nacional, y que pudo justamente ser acusado de ambición y tiranía, desde que se vieron transcurrir tantos meses sin expedir la convocatoria para el solemne congreso de Cortes que invocaban en vano los ciudadanos españoles; resulta de los mismos principios que la Junta Central no pudo transmitir al Consejo de Regencia un carácter de que ella misma carecía, y que la concentración del poder en menor número de individuos escogidos, no por el voto general de los españoles de uno y otro mundo, sino por los mismos que habian sido vocales de la Central, y en un tiempo en que ya no tenían ningún poder que sustituir en las cinco personas

8 Reglamento de 10 de junio de 1810.

9 ibidem.

10 Ibidem. 
señaladas a su arbitrio con el nombre de Regencia, sería tal vez urgente por la energía de las providencias defensivas de la importante plaza de Cádiz y de sus territorios adyacentes; pero debe ser aún más peligrosa y funesta a la libertad interior, y del todo incompetente para los demás reinos y provincias que ni habian tenido parte en su nombramiento ni podian ser dirigidos, administrados y defendidos por ella, y de los cuales, muchos, usando de su derecho habian erigido dentro de sus propios límites el gobierno que exigían las circunstancias y el deseo de no ser vendidos al enemigo común, ni subyugados al imperio de la Francia, por la insuficiencia, desorden o desgracia de otros administradores (...)Es, por último, indisputable que si los habitantes de la España americana no se afrentan de ser racionales, ni de estar llamados al goce de los derechos civiles como ciudadanos españoles, no pueden adherirse a una forma de representación tan parcial como la que se ha prescrito para las dos porciones de nuestro imperio, y que lejos de ajustarse a la igualdad y confraternidad que se nos decantan, sólo está calculada para disminuir nuestra importancia natural y politica. (...)"11

El documento citado parte de una defensa de los principios de participación política y de democracia representativa, así como del concepto de soberanía nacional ${ }^{12}$

"El ejercicio más importante de los derechos del pueblo es aquel en que los transmite a un corto número de individuos, haciéndolos árbitros de la suerte de todos. En este momento decisivo importa más que nunca proscribir el interés personal y aun el de las corporaciones particulares; renunciar y anatematizar los manejos ocultos de la ambición; penetrarse, en fin, de los sagrados deberes que impone la Patria a sus hijos. Todas las clases de hombres libres son llamadas al primero de los goces de ciudadano, que es el concurrir con su voto a la delegación de los derechos personales y reales que existieron originariamente en la masa común y que la ha restituido el actual interregno de la monarquía. Desde el momento en que la más pérfida usurpación arrancando del trono hereditario al Soberano reconocido intentó por la fuerza la instalación de una dinastía extranjera, fue el deber de las autoridades que accidentalmente se encontraron a la cabeza de la nación, solicitar que los pueblos españoles de ambos hemisferios eligiesen sus representantes, ya para encargarlos provisionalmente del depósito de la soberanía, ya para continuar el gobierno que durante la cautividad del monarca, o hasta la exaltación de su sucesor legítimo, debiese administrar los intereses de un imperio tan vasto y defenderlo contra la ambición de la Francia $(. . .)^{13}$

El documento citado parte de una defensa de los principios de participación política y de democracia representativa, así como del concepto de soberanía nacional "Los alcaldes de primera elección en las ciudades y villas, y los tenientes justicias mayores de los pueblos, nombrarán tantos comisionados para la formación de un censo general cuantas sean las parroquias comprendidas en su respectiva 
jurisdicción(... ${ }^{14}$ Cada uno de estos comisionados acompañado del cura de la parroquia, o de otro eclesiástico que haga sus veces, y de otras dos personas respetables de la misma parroquia, procederá inmediatamente a la formación del censo o matrícula del vecindario comprendido en ella. ${ }^{15}$. El censo de la parroquia o cuartel, resultará de la suma total de sus habitantes el número de electores correspondiente a cada una de estas divisiones, arreglándose a razón de uno por cada quinientas almas de todas clases, y aunque su número no llegue a quinientos, nombrarán sin embargo un elector; pero de los sobrantes que resultaren no se hará mérito para el nombramiento de otro elector sino cuando sea de más de 250 almas el exceso; en cuyo caso tendrá este residuo igual derecho que el número de quinientas ${ }^{16 "}$

Establecido el censo parroquial y llevada a cabo la votación por sistema mayoritario a pluralidad de votos, " $N$., vecino de la parroquia $N$. del partido capitular de N., elijo y nombro por elector (electores) de la expresada parroquia a N. Firma del sufragante" y en igualdad de votos se resolverán las dudas por sorteo. ${ }^{17}$

Proclamados los representantes electos en las parroquias, estos se reunirán en las cabezas de partido, donde elegirán por cada veinte mil habitantes un diputado, aunque se garantizará que al menos cuenten con uno aunque la población no llegue a ese número ${ }^{18}$. Posteriormente se levantará el acta correspondiente, donde debe constar el resultado de las lecciones, procediendo al nombramiento de los electos, entregándoles las credenciales acreditativas de su condición de diputados ${ }^{19}$.

El sufragio es de carácter censitario, así el artículo 4 del Capítulo I, proclama restricciones al sufragio por razones de edad, menores de 25 años, ${ }^{20}$ sexo, quedando las mujeres excluidas del derecho al voto, de salud, ya que niega el derecho de participación a los dementes, los sordomudos, así como a los que tuvieran causa criminal abierta, a los deudores a caudales públicos los que hayan sufrido pena corporal, aflictiva o infamatoria, así como por causas económicas, negando el voto a todos los que no tuvieren casa abierta o poblada, esto es, que vivan en la de otro vecino particular a su salario y expensas, o en actual servicio suyo; a menos que, según la opinión

\footnotetext{
Art. 1. Capítulo primero. Reglamento

Art.2. Capítulo primero. Reglamento.

Art. 5. Capítulo primero. Reglamento.

Art. 14. Capítulo primero. Reglamento.

Capítulo II. Art.2.

Capítulo II. Arts. 7 a 16.

Con la excepción de los que estuvieren casados.
} 
común del vecindario, sean propietarios, por lo menos, de dos mil pesos en bienes muebles o raíces libres.

La Democracia representativa se proclama por primera vez en Venezuela en el texto de 1811, primera Carta Magna redactada en castellano, si exceptuamos el texto de Bayona de 1809, que por otra parte no puede ser considerada como un texto constitucional, sino como una Carta otorgada por el Emperador Napoleón I, aunque genéricamente se incluya dentro de las denominadas Constituciones Napoleónicas, junto a los textos de Holanda ,Westfalia, Italia y Suiza, pero que adolecen de una proclamación diáfana del principio de soberanía nacional y no responden a un proceso constituyente de origen popular, sino consecuencia de la voluntad de quien ejerce el poder político en ese momento que es el Emperador francés ${ }^{21}$.

Podemos destacar otros intentos previos de proclamación constitucional en Venezuela, aunque estos fueran de carácter provincial, ${ }^{22}$ tal es el caso de los textos de Barinas, Mérida ${ }^{23}$ y Trujillo ${ }^{24}$.

\section{LA CONSTITUCIÓN DE 1811.}

La Constitución de $1811,{ }^{25}$ que inició su trámite parlamentario el 3 de septiembre y fue aprobada el 21 de diciembre, está claramente inspirada en el texto norteamericano de $1787,{ }^{26}$ proclama el principio de la soberanía nacional, siguiendo la fórmula norteamericana, que emplea el término Pueblo y no Nación como hiciera el texto francés de 1791, aunque a diferencia del primero constituye al Es-

21 Sobre este punto véase Núñez Rivero, Cayetano y Martínez Segarra.;(1997) "Historia constitucional de España". Madrid. Ed. Universitas. Madrid.Pag.49.

22 Véase al respecto Restrepo Piedrahita, Carlos; "Primeras Constituciones de Colombia y Venezuela 1811-1830";Bogotá 1996, pág 37 y ss.

23 El 30 de julio de 1811, el Colegio Electoral de esta provincia, aprobó una Constitución Provisional para esta Provincia; en la misma se proclamaba la división de poderes y se regulaba el Colegio Electoral, compuesto por ocho miembros, electos por sistema indirecto (arts3 a 31), como legítima representación de la Provincia, atribuyéndola Poderes Constituyentes y legislativos.

${ }^{24}$ El 2 de septiembre de 1811 se aprobó un "Plan de Constitución Provisional Gubernativa; el Poder Provincial estaba representado por el Colegio de Electores, elegidos por los pueblos de la Provincia.

25 El Proyecto de Constitución de la nueva República fue encargado a Gabriel Ponte, Juan Germán Roscio y Francisco Javier Ustáriz, que sería su principal ponente.La revisión del Proyecto correspondió a Francisco Iznardi.

26 La influencia del constitucionalismo americano es claramente perceptible en la concepción republicana de gobierno, el carácter presidencial de la Jefatura del Estado,en la estructura federal y el bicameralismo. 
tado en confesional católico excluyente, ${ }^{27}$ al igual que hará el posterior constitucionalismo hispanoamericano del siglo $\mathrm{XIX}^{28}$

"En el nombre de Dios Todo Poderoso, nos, el Pueblo de los Estados de VENEZUELA, usando de nuestra Soberanía y deseando establecer entre nosotros la mejor administración de justicia, procurar el bien general, asegurar la tranquilidad interior, proveer en común a la defensa exterior, sostener nuestra Libertad e Independencia política, conservar pura e ilesa la sagrada religión de nuestros mayores, asegurar perpetuamente a nuestra posteridad el goce de estos bienes y estrecharnos mutuamente con la más inalterable unión y sincera amistad, hemos resuelto confederarnos solemnemente para formar y establecer la siguiente Constitución, por la cual se han de gobernar y administrar estos Estados". 29

No obstante, la proclamación de Soberanía Nacional, quedaría muy mermada, al establecerse el sufragio censitario ${ }^{30}$, como se indicará posteriormente en el presente trabajo.

El principio de democracia representativa se deriva del desarrollo del concepto de Soberanía que define el texto constitucional en el Capítulo VIII, Sección Primera, ${ }^{31}$ así en el art. 144, se proclama “ La soberanía de un país o supremo poder de reglar y dirigir equitativamente los intereses de la comunidad reside, pues, esencial y originariamente en la masa general de sus habitantes y se ejercita por medio de Apoderados o Representantes de éstos, nombrados y establecidos conformes a la Constitución."

\section{Características del sufragio.}
a) Indirecto.

La circunscripción electoral es la provincia, de tal forma, que mediante un sistema indirecto, el dos de noviembre cada dos años, los ciudadanos con derecho a voto se reúnen en la Parroquia para

27 Art.1.C.V.1811." La Religión, Católica, Apostólica, Romana, es también la del Estado y la única y exclusiva de los habitantes de Venezuela. Su protección, conservación, pureza e inviolabilidad será uno de los primeros deberes de la Representación nacional, que no permitirá jamás en todo el territorio de la Confederación, ningún otro culto público, ni privado, ni doctrina contraria a la de Jesucristo."

28 vid Núñez Rivero, cayetano;(2015) "La Religión y el Estado hispanoamericano". Madrid .Ed. Dykinson..

29 Preámbulo

30 Art.26 C.V.1811.

31 Arts 141 a 150. 
elegir a los electores parroquiales, que posteriormente designarán a los representantes que correspondan a esa Provincia ${ }^{32}$.

Para la Cámara de Representantes el mandato dura cuatro años, renovándose cada dos por la mitad. ${ }^{33}$

La población de las Provincias será la que determine el número de Representantes que les corresponda, en razón de uno por cada veinte mil almas de todas condiciones, sexos y edades, renovándose el censo cada cinco años y si hechas las divisiones de veinte mil, resultare algún residuo que pase de diez mil, habrá por él un Representante más. ${ }^{34}$ Esta proporción de uno por veinte mil, continuará siendo la regla de representación, hasta que el número de los Representantes llegue a sesenta; y aunque aumentase la población no se aumentará por eso el número, sino se elevará la proporción hasta que corresponda un Representante a cada treinta mil almas. En este estado continuará la proporción de uno por treinta mil, hasta que lleguen a ciento los Representantes; y entonces como en el caso anterior, se elevará la proporción a cuarenta mil por uno hasta que lleguen a doscientos por el aumento progresivo de la población, en cuyo caso se procederá de modo que la regla de proporción no suba de uno por cincuenta mil almas. ${ }^{35}$ En la Parroquia corresponderá un elector por cada mil almas, manteniéndose este elector, aunque no llegue a dicho número los miembros de la misma. ${ }^{36}$

Para el Senado, cada Provincia contará con un Senador al menos y otro por cada setenta mil almas de la misma, y en su caso por aquel Estado que cuente con una cuota de treinta mil. ${ }^{37}$

b) Sufragio Censitario.

\section{b.1.Activo.}

El artículo 26, proclama el carácter restrictivo se sufragio “ Todo hombre libre tendrá derecho de sufragio en las Congregaciones Parroquiales, si a esta calidad añade la de ser Ciudadano de Venezuela, residente en la Parroquia o Pueblo donde sufraga: si fuere mayor de veintiún años, siendo soltero o menor siendo casado y velado y si poseyere un caudal libre del valor de seiscientos pesos en la Capitales de Provincia siendo soltero y de cuatrocientos siendo casado, aunque pertenez-

\footnotetext{
32 Art.21. C.V.1811.

Art.14. C.V.1811.

Art.17. C.V.1811.

Art. 18. C.V.1811.

36 Art.22. C.V.1811.

37 Art.46. C.V.1811.
}

(C) UNED. Revista de Derecho UNED, núm. 27, 2021 
can a la mujer o de cuatrocientos siendo en las demás poblaciones en el primer caso y doscientos en el segundo; o si tuviere grado, u aprobación pública en una ciencia o arte liberal o mecánica; o si fuere propietario o arrendador de tierras, para sementeras o ganado con tal que sus productos sean los asignados para los respectivos casos de soltero u casado". ${ }^{38}$

A lo que debe añadirse lo indicado en el artículo 27, "Serán excluidos de este derecho los dementes, los sordomudos, los fallidos, los deudores a caudales públicos con plazo cumplido, los extranjeros, los transeúntes, los vagos públicos y notorios, los que hayan sufrido infamia no purgada por la Ley, los que tengan causa criminal de gravedad abierta y los que siendo casados no vivan con sus mujeres, sin motivo legal.» ${ }^{39}$ Un tema que provocó numerosas discusiones en el debate constituyente fue el de la consideración de los Pardos, con derecho al voto y la representación, pues mientras los diputados de las provincias se inclinaban porque fueran las legislaturas locales las que decidieran sobre la concesión de estos derechos a los individuos de color, los de las capitales eran partidarios de que fuera un acto de carácter nacional; el resultado final fue que no se hiciera distinción respecto a la raza en la proclamación de los derechos de igualdad. ${ }^{40}$

Además de las cualidades referidas para los sufragantes parroquiales, los que han de tener voto en las Congregaciones electorales, deben ser vecinos del Capitular donde votaren y poseer una propiedad libre de seis mil pesos en la Capital de Caracas, siendo solteros y de cuatro mil siendo casados, cuya propiedad será en las demás Capitales, Ciudades y Villas, de cuatro mil siendo soltero y tres mil siendo casado. ${ }^{41}$

Ni los sufragantes Parroquiales, ni los Electores capitulares recibirán recompensa alguna del Estado por concurrir a sus respectivas Congregaciones y ejercer en ellas lo que previene la Constitución, aunque sea necesario a veces emplear algunos días para concluir lo que ocurriere. ${ }^{42}$

Debe destacarse igualmente, que los representantes están sujetos a mandato revocatorio, si incurren en el delito de compra o venta de votos, o de haber procurado la elección de algún individuo con

38 Art.26. C.V.1811.

39 Art. 27. C.V.1811.

40 .En el Cabildo de Caracas, desde abril de 1810 existía un representante de los Pardos, D. José Felix Ribas.

41 Art.28. C.V.1811.

42 Art.213. 
amenazas, intrigas, artificios, u otro género de seducción, siendo excluido de la Asamblea y del ejercicio de toda función pública por espacio de veinte años, y en caso de reincidencia, la exclusión será perpetua. ${ }^{43}$

\section{b.2. Sufragio Pasivo.}

Para la Cámara de representantes, el texto constitucional no especifica otras limitaciones de carácter económico, aunque sí referentes a limitaciones de edad, que sitúa en veinticinco años ${ }^{44}$.

Respecto al Senado, que asigna al menos un senador por provincia, más uno por cada setenta mil almas, o un residuo de treinta mil, ${ }^{45} \mathrm{el}$ texto constitucional proclama que el candidato ha de contar con una propiedad de sesenta mil pesos ${ }^{46}$, a lo que debe unirse la calidad de residencia de diez años en el territorio de Venezuela, con las excepciones previstas, al igual que los miembros de la Cámara de Representantes, previstas en el artículo dieciséis. ${ }^{47}$

Tras la escasa vigencia del texto constitucional de 1811 y estando el país sumido en guerra contra las tropas españolas y disuelto el primer Congreso por la capitulación de 26 de julio de 1812, desde el Cuartel de Angostura, Simón Bolivar, mandaba publicar el Reglamento para la Segunda Convocatoria del Congreso de Venezuela, ${ }^{48}$ en el que se hacen numerosas referencias a la situación bélica y a la derrota de las tropas venezolanas y a la extinción del primer Congreso venezolano, introduce muy claramente el concepto de que los diputados electos al Congreso no sólo serán representantes de su provincia, sino de toda la Nación, "de tal manera que ninguno de los que resultaren nombrados ha de ceñir sus ideas ni su representación al distrito de su nombramiento, ni siquiera a cualquier otro particular, sino generalmente a todas y cada una de las porciones de Venezuela...A la unidad e indivisibilidad de la República importa la unidad de sus Diputados. Consérvese para otros fines la División topográfica de parroquias, departamentos capitulares y provinciales; pero desprenderse

43 Art.212.

44 Art. 15.CV.1811.

45 Arts. 45 y 46. CV.1811.

46 Art.49. . CV.1811.

47 "La condición de domicilio y residencia requerida aquí para los Representantes, no excluye a los que hayan estado ausentes en servicio del Estado, ni a los que hayan permanecido fuera de él con permiso del Gobierno en asuntos propios, con tal que su ausencia no haya pasado de tres años; ni a los naturales del territorio de Venezuela, que habiendo estado fuera de él, se hubiesen restituido y hallado presentes a la declaratoria de su absoluta Independencia y la hubiesen reconocido y jurado".

48 Correo del Orinoco de 24 de octubre de 1818 n$^{\circ}$ s 14 y 15. 
los Diputados del espíritu de Provincia, y considerarse como Representantes de todos, y cada uno de los distritos de Venezuela". Introduce como sedes de votación las plazas, campos y otras posiciones militares, aunque no en un sentido estricto de circunscripción electoral, que queda reservado a las Parroquias, "Siendo del fuero de guerra casi todos los sufragantes y estando la mayor parte de ellos reunidos en plazas, campos...serán estos los parages mas a proposito para la elección,; pero no por eso dexará de hacerse en las Parroquias libres afin de que no sean defraudados de este derecho los Ciudadanos que en ellas residan y sean capaces de elegir".

Igualmente en el citado Reglamento, introduce una dimensión continental a la representación de los diputados, "Nuestros Diputados pues aunque por el momento hayan de contraer sus funciones a los términos de Venezuela, formarán la dulce idea de que en el exercicio de ellas van a promover el bien de toda la América insurrecta contra el poder arbitrario de la España. Se imaginarán también nombrados por las demás Secciones de nuestro hemisferio oprimido y como tales, reunidos en Congreso, jamás perderán de vista el grandioso quadro de todas ellas; el conjuto de todos sus hijos y la gloria de haber cooperado eficazmente a la emancipación y libertad de todos ellos".

El Reglamento se proclaman los requisitos de participación política, encuadrados en el Sufragio Censitario:

a) Ciudadanos propietarios de al menos 21 años, que contaran con una propiedad o profesaren alguna ciencia o arte liberal o mecánica.(no se indica el valor de la propiedad).Se incluyen en este concepto a los propietarios de tierras que estuvieren en posesión del enemigo.

b) El derecho de sufragio se extiende a los arrendadores de tierras y ganado si cuentan con un fondo de trescientos pesos al menos.

c) Se excluye del sufragio activo y pasivo a los dementes, los sodomudos, los deudores a caudales públicos con plazo cumplido, los extranjeros que no sirvan a la República, los vagos, desertores, los procesados por causa principal abierta y los casados que sin razón legal estén separados de sus mujeres.

d) Se incluye en el derecho de sufragio a los empleados civiles y militares, que estén dotados con al menos 200 pesos anuales. 
e) Se concede el derecho de sufragio a los oficiales, sargentos y cabos al servicio de la República.

f) Del resto de la tropa, sólo sufragan los que sean padres de familia, propietarios de bienes raíces o arrendadores de la tierra, como se indica en el punto anterior correspondiente.

g) Los inválidos por causa de guerra, gozaban igualmente del derecho de participación política.

\section{LA CONSTITUCIÓN DE 1819.}

La Constitución de 1819, sancionada en Angostura, capital de la Guayana, es de todos los textos constitucionales venezolanos, el más profundamente inspirado en el pensamiento de Simón Bolivar, ${ }^{49}$ que ostentaba en ese momento el cargo de Jefe Supremo de la República. Sobre esa línea de pensamiento debe destacarse, que a diferencia del texto de 1811, proclama el Estado Unitario, del que Simón Bolivar era claramente partidario, como consecuencia de la emergencia de caudillos locales y regionales surgidos durante el amplio periodo de la Guerra de Independencia, y que dificultaban enormemente la vida de un Gobierno centralizado. Este pensamiento de Bolivar se percibe claramente en su manifiesto de Cartagena de 15 de diciembre de $1812,{ }^{50}$ así como su carta de Jamaica de 6 de septiembre de $1815,{ }^{51}$ y en su mensaje al Congreso de Angostura del 15 de febrero de 1819.

De hecho, el mandato de Bolivar, en su proceso de reconquista del país desde 1813 hasta 1919, es de carácter dictatorial y de carácter de caudillo militar personalista, y sólo a partir de 1818, cuando ya mantiene su poder sobre la mayoría del territorio venezolano, no se plantea dar una forma jurídica al país.

El 22 de octubre de 1818 se convocaron elecciones para formar un Congreso Constituyente; las elecciones se llevaron a cabo en con-

49 Véase al respecto Ed. Pedro Grases; “El Liberador y la Constitución de Angostura”; Publicaciones del Congreso de la República. Caracas.1969.

50 "Yo soy del sentir que mientras no centralicemos nuestros Gobiernos americanos, los enemigos obtendrán las más completas ventajas...(si los gobiernos) son calamitosos y turbulentos, él debe mostrarse terrible y armarse de una forma igual a los peligros, sin atender a leyes ni constituciones ínterin no se restablezca la felicidad y la paz"

51 "Los acontecimientos de tierra firme nos han probado que las constituciones perfectamente representativas no son adecuadas a nuestro carácter, costumbres y luces actuales". 
diciones extremas, en pocos territorios y entre las filas del ejército, saliendo cinco diputados por las provincias liberadas ${ }^{52}$.

El 15 de febrero de 1819, se constituyó el Congreso en la ciudad de Angostura, renunciando Bolivar a sus plenos poderes y siendo designado por el Congreso Presidente de la República. ${ }^{53}$

La representación política se pone de manifiesto desde el Título 5 , en su artículo $1^{\circ}$, en el que proclama que la soberanía de la nación reside en la universalidad de los ciudadanos y que es imprescriptible e inseparable del pueblo, resaltando en el artículo siguiente la importancia de las elecciones "El pueblo de Venezuela no puede ejercer por sí otras atribuciones de la soberanía que la de las elecciones..." ${ }^{54}$

La Constitución de quince de agosto de 1819, segunda que se proclama en el país, sigue el mismo sendero iniciado en el texto de 1811 ,de votación indirecta en segundo grado y sufragio de carácter restringido.

El texto proclama de forma diáfana y explícita el carácter de democracia representativa, optando por la teoría francesa de la misma, así el artículo $8^{\circ}$ del título 6 de la sección primera, manifiesta " Los Representantes tienen este carácter por la Nación, y no por el Departamento que los nombra. Ellos no pueden recibir órdenes, ni instrucciones particulares de las Asambleas Electorales, que sólo podrán presentarles peticiones".

\section{Características del sufragio.}

El carácter censitario del sufragio se proclama por primera vez en El título 3 sección Primera ${ }^{55}$, donde divide a la ciudadanía en activos y no activos. siendo los primeros los que gozan el derecho de sufragio, y ejercen por medio de él la Soberanía Nacional, nombrando sus representantes,.${ }^{56} \mathrm{denominando}$ como pasivos a aquellos que estando bajo la protección de la ley, no tienen parte en su for-

52 Las provincias de Mérida, Trujillo, Maracaibo y Coro no pudieron ser representadas por estar bajo el control de la Corona.

53 Cabe destacar, que el mismo día dirigió un mensaje al Cngreso en el que manifestaba "Cuanto más admiro la excelencia de la Constitución Federal de Venezuela tanto más me persuado de la imposibilidad de su aplicación a nuestro Estado".

54 Art. $2^{\circ}$. Título 5.

55 Art. $1^{\circ}$.

56 Art. $2^{\circ}$. 
mación, no ejercen la Soberanía Nacional, ni gozan del derecho de sufragio. ${ }^{57}$

Los requisitos para el ejercicio del derecho de sufragio son de carácter residencial, edad, capacidad cultural y de carácter económico.

De carácter residencial se precisa haber nacido en el territorio de la República, y tener domicilio o vecindario en una de sus parroquias ${ }^{58}$;respecto a la edad, se precisa contar con veintiún años o en su defecto ser casado ${ }^{59}$;en cuanto a la capacidad cultural, se restringe el voto a los analfabetos ${ }^{60}$; las condiciones económicas para ser considerado ciudadano activo consistían en la posesión de una propiedad en el territorio del Estado con valor de quinientos pesos, aunque esta falta de propiedad podía suplirse, si se contaba con ,la posesión de algún grado, o aprobación pública en una ciencia, o arte liberal o mecánica así como si contaba con un grado militar vivo y efectivo, o de algún empleo con renta de trescientos pesos por año. ${ }^{61}$

El texto manifiesta que el sufragio activo podía perderse por las siguientes causas: a) Por ausentarse del territorio de la República por cuatro años continuos, no siendo en comisión, o servicio de ella, o con licencia del Gobierno; ${ }^{62} \mathrm{~b}$ ) Por haber sufrido una pena aflictiva, o infamatoria, hasta la rehabilitación; ${ }^{63}$ c) Por haber sido condenado en un juicio por haber vendido su sufragio, o comprado el de otro para sí, o para un tercero, bien sea en las asambleas primarias, en las electorales, o en otras. ${ }^{64}$

Tampoco gozaban del derecho de sufragio, las mujeres, ni los locos, o dementes ${ }^{65}$, los deudores fallidos y vagos, declarados como tales ${ }^{66}$, ni los deudores a caudales públicos con plazo cumplido ${ }^{67}$. Destaca por su carácter novedoso en el constitucionalismo y que sólo puede tener sus raíces difusas en el Derecho Indiano, la retirada del derecho al sufragio, a los que estando casados no vivieran con sus esposas sin motivo legal. ${ }^{68}$

57 Art. $3^{\circ}$.

58 Art. $4^{\circ}$.Primero.

59 Art. $4^{\circ}$. Segundo.

60 Art. 4. Tercero. No obstante lo indicado, la condición de saber leer y escribir no se exigiría hasta 1830 .

61 Art. $4^{\circ}$.Cuarto.

62 Art. $8^{\circ}$.Primero.

63 Art. $8^{\circ}$.Segundo.

64 Art. $8^{\circ}$. Tercero.

5 Art. $9^{\circ}$. Primero.

66 Art. $9^{\circ}$.Segundo.

67 Art. $9^{\circ}$. Cuarto.

68 Art. $9^{\circ}$.Quinto. 
Destaca igualmente, que pese a la proclamación restrictiva del sufragio, sin embargo el texto abre la posibilidad de la participación política a los extranjeros, siempre que cumplan las siguientes condiciones, a) Haber obtenido carta de naturaleza en recompensa de algún servicio importante hecho a la República, si tuvieran la edad exigida a los naturales, y si supieran leer y escribir ${ }^{69}$;b) y aún no teniendo la carta de naturaleza, si cumpliendo los requisitos indicados anteriormente de edad u capacidad intelectual, hayan residido en el territorio de la República un año continuo y estén domiciliados en alguna parroquia, hayan manifestado su intención de establecerse en la República, casándose con una venezolana o trayendo su familia a Venezuela, así como contar con una propiedad raíz valor de quinientos pesos o ejerzan alguna ciencia, arte liberal o mecánica. ${ }^{70}$

Las condiciones para el sufragio pasivo son más restrictivas, concretándose en las siguientes:

\section{Cámara de Representantes}

a) Todas las cualidades para ser ciudadanos activos, indicadas anteriormente.

b) Edad de veinticinco años cumplidos.

c) Cinco años de vecindad en el territorio de la República, inmediatamente antes de la elección. La condición de vecindad requerida aquí para los Representantes no excluye a los que hayan estado ausentes en servicio del Estado ni a los que hayan permanecido fuera de él con permiso del Gobierno en asuntos propios, con tal que su ausencia no haya pasado de tres años.

d) Tener una propiedad de cinco mil pesos en bienes raíces, o renta de quinientos pesos anuales, o la profesión de una ciencia o arte liberal. ${ }^{71}$

71 Art. $2^{\circ}$.Título 6. Sección segunda. 


\section{Senado. ${ }^{72}$}

Para ser Senador, se necesita además de las calidades de ciudadano activo:

a) Edad de Treinta años de edad.

b) Diez años de residencia en el territorio de la República, inmediatamente antes de la elección, a menos que su ausencia haya sido en comisión, o servicio de ella. Hasta el año de 1825, bastará haber emprendido la campaña de 1816, y haber continuado sus servicios hasta el día de la elección.

c) Una propiedad de ocho mil pesos en bienes raíces, o la renta correspondiente a este capital.

d) Y haberse distinguido en el ejercicio de destino público. ${ }^{73}$

Los extranjeros pueden gozar del sufragio pasivo, si cumplen las siguientes condiciones:

a) Gozar de las cualidades manifestadas en los artículos $5^{\circ}$ y $6^{\circ}$ del título 3 , sección primera, ya indicadas en párrafo precedente del presente trabajo.

b) Estar casados.

c) Tener su familia en el país.

d) Treinta mil pesos en bienes raíces.

e) Haber hecho servicios muy importantes a la República ${ }^{74}$

Los Obispos estaban exentos de cumplir los requisitos indicados, siendo miembros honorarios del Senado, ${ }^{75}$ como consecuencia del carácter confesional católico imperante en la República de Venezuela desde su acceso a la independencia. ${ }^{76}$

72 El Congreso Constituyente no se aprobó la propuesta de Simón Bolivar de que el Senado tuviera un carácter hereditario.

73 Art. $6^{\circ}$. Sección tercera.

74 Art. $6^{\circ}$.

75 Art. $7^{\circ}$.

76 Vid al respecto. NÚÑEZ RIVERO; ob.an.cit.págs 90 a 99. 


\section{El carácter indirecto del sufragio}

El sistema de elección indirecta se mantiene para todas las formas de elecciones de carácter de representación política, tanto para las de carácter municipal, como para las correspondientes a la Cámara de Representantes, Senado y Presidenciales.

De la misma forma que en la convocatoria electoral de 1810, o en el texto del mismo año, en la Parroquia se encuentra la base de la representación, que se conforma por los ciudadanos activos no suspensos, vecinos de la misma, ${ }^{77}$ que deben nombrar al elector o electores que correspondan a la misma ${ }^{78}$;Las elecciones son públicas, así como su recuento, llevado a cabo en presencia de los votantes ${ }^{79}$. Posteriormente se constituirán las Asambleas Departamentales, que procederán a nombrar al representante o representantes que correspondan al Departamento, así como a un número igual de suplentes, que sustituirán a los primeros en caso de fallecimiento, dimisión, destitución o grave enfermedad y ausencia necesaria ${ }^{80}$.

No obstante el carácter indirecto y restringido que proclama el texto constitucional, es digno de resaltar que en el artículo $8^{\circ}$ se prevé que en el futuro las elecciones harían por el pueblo y no por los electores ${ }^{81}$.

Las elecciones al Presidente de la República ${ }^{82}$ se llevan a cabo igualmente mediante el sistema indirecto, comenzando el proceso en las Asambleas Electorales indicadas anteriormente ${ }^{83}$, de tal forma que cada elector votará los nombres de de dos ciudadanos de la República ${ }^{84}$; concluida la votación, su resultado se remite al Senado, cuyo Presidente lo remitirá a las dos cámaras, que se reunirán sesión conjunta y procederán al escrutinio de los candidaturas propuestas, proclamándose como Presidente el que hubiere obtenido las dos terceras partes de los electores departamentales, y el que le siguiere en número de votos será declarado Vicepresidente de la República ${ }^{85}$.

\footnotetext{
77 Art. $2^{\circ}$.Título 4. Sección primera.

78 Art. $4^{\circ}$.

79 Art. $6^{\circ}$

80 Arts $1^{\circ}$ a $3^{\circ}$. Sección Segunda.

81 "Pasados diez años, las elecciones se harán inmediatamente por el pueblo, y no por medio de electores"

82 El Congeso Constituyente no aprobó la propuesta de Simón Bolivar de que la Presidencia de la República tuviera un carácter vitalicio, aunque sí la dotó de amplias atribuciones.

83 Vid Sección segunda del título cuarto, ya citado.

84 Art. $3^{\circ}$.Título 7. Sección segunda.

85 Arts $4^{\circ}$ a $8^{\circ}$.
} 
Si ninguno hubiere alcanzado estas mayorías, el Congreso separa los seis que obtengan el mayor número de votos, elige dos entre estos. El que obtuviere en esta elección la mayoría absoluta de los miembros presentes, es el Presidente, y el que le siga será Vicepresidente. En caso de igualdad la suerte decide. ${ }^{86}$. La elección del Presidente y Vicepresidente, se hará en una sola sesión que será permanente ${ }^{87}$.

\section{REFERENCIAS.}

Constitución Federal para los Estados de Venezuela de 1810.

Constitución de Venezuela de 1819.

Decreto de la Junta Central Suprema de España de 22 de enero de 1809.

Jovellanos, Melchor Gaspar; "Memorandum al Rey Carlos IV". En Obras completas. (1846).Madrid. Biblioteca de Autores españoles.

LYNCH, JUAN; (2005)"La revolución hispanoamericana 1808-1826". Ed. Ariel. Barcelona .

Núñez Rivero, Cayetano, Martínez Segarra, Rosa.(1997); "Historia constitucional de España". Madrid. Ed. Universitas.

NúÑEz Rivero, CaYetano;(2015)."La Religión y el Estado hispanoamericano". Madrid .Ed. Dykinson.

Restrepo Piedrahita, Carlos; (1996); "Primeras Constituciones de Colombia y Venezuela 1811-1830”;Bogotá .Universidad del Externado.

Reglamento para la elección y reunión de diputados que han de componer el Cuerpo Conservador de los Derechos del Sr. D. Fernando VII en las Provincias de Venezuela de 10 de junio de 1810.

"Reglamento para la Segunda Convocatoria del Congreso de Venezuela"; Correo del Orinoco de 24 de octubre de 1818 nº 14 y 15.

Pedro Grases; (1969) "El Liberador y la Constitución de Angostura"; Publicaciones del Congreso de la República. Caracas.

Simón Bolivar; "Manifiesto de Cartagena de 15 de diciembre de 1812;",Carta de Jamaica de 6 de septiembre de 1815;"Mensaje al Congreso de Angostura del 15 de febrero de 18192.

87 Art.12. 
